\title{
CURAHAN WAKTU KERJA WANITA DALAM KEGIATAN USAHATANI PADI SAWAH DI DESA RASI SATU KECAMATAN RATAHAN KABUPATEN MINAHASA TENGGARA
}

\author{
Asti Unu \\ Martha M. Sendow \\ Welson M. Wangke
}

\begin{abstract}
The aim of the study was to find out the time allocation of women's activities in wetland rice farming in the form of nursery activities, planting, weeding, fertilizing, harvesting until processing land, and controlling pests and diseases only carried out by men. The outpouring of a woman's work time in productive activities depends a lot on socio-economic factors and the condition of her family. Socio-economic factors that influence the outpouring of working time for female farmers are age level, number of family dependents, wage level, land area, marital status, education level, and level of experience. The study lasted for 4 (four) months starting from April to July 2018 in Rasi Satu Village, Ratahan District, Southeast Minahasa Regency. The data used are primary data collected through interviews with 20 women farmers as respondents. Secondary data was obtained from the Rasi Satu Village office. The analysis used is descriptive in table form. The results showed that the outpouring of working time of women in wetland farming in Rasi Satu Village was at nursery activities of $6.86 \%$, planting of $22.08 \%$, weeding of $20.26 \%$, fertilization of $10.06 \%$, harvest of $40.74 \%$. But land management, and control of pests and diseases is only done by men. *eprm*.
\end{abstract}

Keywords: outpouring of women's work time, rice paddy farming, Rasi Satu Village, Ratahan Subdistrict, Southeast Minahasa Regency.

\begin{abstract}
ABSTRAK
Tujuan penelitian yaitu mengetahui alokasi waktu kegiatan wanita usahatani padi sawah berupa kegiatan persemaian, penanaman, penyiangan, pemupukan, panen sampai pengolahan lahan, dan pengendalian hama dan penyakit hanya dilakukan oleh laki-laki. Curahan waktu kerja wanita dalam kegiatan yang produktif banyak tergantung pada faktor sosial ekonomi dan keadaan keluarganya. Faktorfaktor sosial ekonomi yang berpengaruh pada curahan waktu kerja wanita tani adalah tingkat umur, jumlah tanggungan keluarga, tingkat upah, luas lahan, status perkawinan, tingkat pendidikan, dan tingkat pengalaman. Penelitian berlangsung selama 4 (empat) bulan mulai dari bulan April sampai bulan Juli 2018 di Desa Rasi Satu, Kecamatan Ratahan, Kabupaten Minahasa Tenggara. Data yang digunakan yaitu data primer yang dikumpulkan melalui wawancara pada 20 wanita tani sebagai responden. Data sekunder diperoleh dari kantor Desa Rasi Satu. Analisis yang digunakan yaitu secara deskriptif dalam bentuk tabel. Hasil penelitian menunjukkan bahwa curahan waktu kerja wanita dalam usahatani padi sawah di Desa Rasi Satu yaitu pada kegiatan persemaian $6,86 \%$, penanaman $22,08 \%$, penyiangan $20,26 \%$, pemupukan $10,06 \%$, panen $40,74 \%$. Namun pengolahan lahan, dan pengendalian hama dan penyakit hanya dilakukan oleh laki-laki.
\end{abstract}

Kata kunci: curahan waktu kerja wanita, usahatani padi sawah, Desa Rasi Satu, Kecamatan Ratahan Kabupaten Minahasa Tenggara. 


\section{PENDAHULUAN}

\section{Latar Belakang}

Sebagian besar penduduk Indonesia tinggal di pedesaan dan sektor kerja dan sektor pertanian telah menjadi sektor paling utama dalam pengarapan tenaga kerja. Tenaga kerja merupakan salah satu aspek paling penting dalam berbicara tenaga usahatani. Dalam usahatani dikenal ada tiga jenis tenaga kerja yaitu tenaga kerja manusia, tenaga kerja hewan, dan tenaga kerja mesin atau mekanis. Sedangkan tenaga kerja manusia terbagi dalam tiga jenis pula yaitu tenaga kerja pria, tenaga kerja wanita, dan tenaga kerja anak. Adanya perkembangan peran dan posisi kaum wanita yang sejak dahulu telah menempatkan wanita sebagai mitra yang sejajar dengan kaum pria, maka fenomena wanita berkerja pada sektor pertanian bagi masyarakat bukanlah hal yang tidak mungkin terjadi. Karna mayoritas mata pencarian penduduk desa adalah bertani maka kebanyakan wanita yang ikut bekerja dalam membantu perekonomian keluarga pada akhirnya berkerja pula di bidang pertanian.

Peran wanita di sektor pertanian adalah sesuatu yang tidak terbantahkan. Dalam usahatani tanaman pangan, pembagian kerja antara pria dan wanita sangat jelas terlihat, sering dikatakan bahwa pria bekerja untuk kegiatan yang banyak menggunakan otot dan wanita bekerja untuk kegiatan yang memerlukan ketelitian dan kerapihan atau yang banyak memakan waktu (Sudarta, 2003). Dalam pertanian, wanita tidak hanya berperan sebagai ibu rumah tangga saja, namun ditemui pula wanita yang berperan atau secara langsung memberi kontribusi nyata terhadap usaha tani yang diusahakan oleh keluarga itu sendiri.

Kegiatan usahatani yang dilakukan wanita tani dipengaruhi oleh curahan waktu kerja. Curahan waktu kerja wanita dalam kegiatan yang produktif banyak tergantung pada faktor sosial ekonomi dan keadaan keluarganya. Faktor-faktor sosial ekonomi yang berpengaruh pada curahan waktu kerja wanita tani adalah tingkat umur, jumlah tanggungan keluarga, tingkat upah, luas lahan, status perkawinan, tingkat pendidikan, dan tingkat pengalaman (Novita, 2012).
Desa Rasi Satu yang masuk dalam Kecamatan Ratahan Kabupaten Minahasa Tenggara. Dengan demikian perlunya dilakukan penelitian, mengenai curahan waktu kerja wanita dalam kegiatan usahatani padi sawah di Desa Rasi Satu Kecamatan Ratahan.

Dalam Penelitian Martha M Sendow (2001), dengan judul Peranan Wanita Pada Usaha Tani Padi Sawah di Kecamatan Tompaso Kabupaten Minahasa Peranan wanita dalam kegiatan usaha tani padi sawah lebih dominan dibanding pria. Artinya bahwa dalam melakukan proses produksi, wanita mengerjakan hampir semua kegiatan kecuali mengolah tanah/membajak, bahkan turut melakukan pemasaran hasil produksi.

\section{Perumusan Masalah}

Berdasarkan latar belakang, maka masalah dalam penelitian ini adalah bagaimana curahan waktu kerja wanita dalam kegiatan usahatani padi sawah di Desa Rasi Satu Kecamatan Ratahan Kabupaten Minahasa Tenggara?

\section{Tujuan Penelitian}

Mengetahui curahan waktu kerja wanita dalam kegiatan usahatani padi sawah di Desa Rasi Satu Kecamatan Ratahan Kabupaten Minahasa Tenggara.

\section{Manfaat Penelitian \\ Penelitian ini bermanfaat untuk} menambah pengetahuan bagi penulis dan memberikan informasi kepada masyarakat tentang curahan waktu kerja wanita dalam kegiatan usahatani padi sawah di Desa Rasi Satu Kecamatan Ratahan Kabupaten Minahasa Tenggara sekaligus menambah wawasan dan referensi bagi penelitian selanjutnya.

\section{METODE PENELITIAN}

\section{Lokasidan Waktu Penelitian}

Penelitian ini dilaksanakan selama empat bulan yaitu dari bulan April sampai bulan Juli 2018, mulai dari persiapan sampai penyusunan laporan penelitian. Tempat penelitian adalah di Desa Rasi Satu Kecamatan Ratahan Kabupaten Minahasa Tenggara. 


\section{Metode Pengumpulan Data}

Penelitian ini menggunakan data primer dan data sekunder. Data primer diperoleh melalui wawancara langsung pada wanita tani padi sawah tentang persemaian, pengolahan tanah, penanaman, penyiangan, pemupukkan, pengendalian hama dan penyakit, dan panen, dengan menggunakan daftar pertanyaan yang telah disiapkan berupa kuesioner, sedangkan data sekunder diperoleh dari kantor Desa Rasi Satu Kecamatan Ratahan serta instansi yang terkait dalam penelitian ini.

\section{Metode Pengambilan Sampel}

Pengambilan sampel dalam penelitian ini menggunakan metode (purposive sampling) yaitu dengan pengambilan sampel secara sengaja yaitu 20 responden wanita dalam kegiatan usahatani padi sawah.

\section{Konsep Pengukuran Variabel}

1. Umur Responden (tahun)

2. Pendidikan Responden (SD, SMP, SMA, D3, S1)

3. Jumlah Tanggungan Keluarga (jiwa)

4. Luas Tanam (ha)

5. Curahan Kerja Wanita yang digunakan dalam usahatani padi sawah, pada kegiatan:
a. Persemaian (jam/hari)
b. Pengolahan Tanah (jam/hari)
c. Penanaman ((jam/hari)
d. Penyiangan (jam/hari)
e. Pemupukan (jam/hari)
f. Pengendalian Hama dan Penyakit (jam/hari)
g. Panen (jam/hari)

\section{Metode Analisis Data}

Data yang dikumpulkan pada penelitian ini disusun secara deskriptif. Dimana data yang terkumpul disajikan dalam bentuk tabel.

\section{HASIL DAN PEMBAHASAN}

\section{Deskripsi Lokasi Penelitian}

Jumlah penduduk Desa Rasi Satu Kecamatan Ratahan dengan jumlah penduduk 1.196 jiwa yang terdiri dari 608 jiwa laki-laki dan 588 jiwa perempuan yang terhimpun dalam jumlah Kepala Keluarga 310 KK.

\section{Keadaan Geografis Lokasi Penelitian}

Ratahan adalah salah satu kecamatan di Kabupaten Minahasa Tenggara Provinsi Sulawesi Utara. Jarak ke Ibukota Kecamatan 4 $\mathrm{Km}$, Jarak ke Ibukota Kabupaten $4 \mathrm{Km}$ dan Jarak ke Ibukota Provinsi 98 Km.

Adapun batas-batasnya adalah sebagai berikut :

1. Sebelah Utara : Desa Tosuraya Barat

2. Sebelah Timur : Desa Rasi

3. Sebelah Selatan : Desa Tosuraya Selatan

4. Sebelah Barat : Desa Towuntu

\section{Umur}

\section{Karakteristik Responden}

Umur yang produktif pada usia 16 tahun sampai 60 tahun, jika diatas 60 tahun maka usia fisik petani semakin menurun dan produktivitas dalam usahatani bisa berkurang. Jumlah Petani menurut kelompok umur dapat dilihat pada Tabel 1.

Tabel 1. Jumlah dan Persentase Petani Responden Menurut Kelompok Umur

\begin{tabular}{lccc}
\hline No. & $\begin{array}{c}\text { Umur } \\
\text { (Tahun) }\end{array}$ & $\begin{array}{c}\text { Jumlah } \\
\text { Responden } \\
\text { (Orang) }\end{array}$ & $\begin{array}{c}\text { Persentase } \\
(\%)\end{array}$ \\
\hline 1. & $35-40$ & 6 & 30 \\
2. & $45-50$ & 9 & 45 \\
3. & $>55$ & 5 & 25 \\
\hline Jumlah & & 20 & 100 \\
\hline
\end{tabular}

Sumber Data : Diolah dari data primer 2018

Hasil penelitian menunjukkan bahwa kelompok umur 45 sampai 50 memiliki jumlah responden terbanyak sebesar 8 responden atau $40 \%$ dan dapat menunjukkan bahwa sebagian besar responden dapat dikatakan masih dalam usia produktif.

\section{Tingkat Pendidikan}

Pendidikan sangat penting dalam meningkatkan pendapatan petani dan cara berpikir petani dalam mengurangi biaya dan meningkatkan produksi usahatani. Semakin tinggi tingkat pendidikan seseorang maka semakin muda seorang petani dalam menjalankan usahanya. Berdasarkan hasil penelitian, tingkat pendidikan petani dapat dilihat pada Tabel 2 . 
Tabel 2. Jumlah dan Persentase Responden Menurut Tingkat Pendidikan

\begin{tabular}{lccc}
\hline No & Pendidikan & $\begin{array}{c}\text { Jumlah } \\
\text { Responden } \\
\text { (Orang) }\end{array}$ & $\begin{array}{c}\text { Persentase } \\
(\%)\end{array}$ \\
\hline 1. & SD & 11 & 55 \\
2. & SMP & 6 & 30 \\
3. & SMA & 3 & 15 \\
\hline Jumlah & \multicolumn{3}{c}{20} \\
\hline
\end{tabular}

Sumber Data : Diolah dari data primer, 2018

Hasil penelitian menunjukkan bahwa tingkat pendidikan petani di Desa Rasi Satu, memiliki tingkat pendidikan terbanyak yaitu 55\% pada tingkat pendidikan Sekolah Dasar (SD), sedangkan $30 \%$ berada pada tingkat pendidikan SMP dan pada tingkat pendidikan SMA hanya mencapai $15 \%$.

\section{Jumlah Anggota Keluarga}

Jumlah angota keluarga adalah jumlah orang yang masih menjadi tanggungan dalam satu keluarga. keadaan jumlah anggota keluarga dapat dilihat pada Tabel 3 .

Tabel 3. Jumlah dan Persentase Petani Menurut Jumlah Tanggungan

\begin{tabular}{ccc}
\hline $\begin{array}{c}\text { Jumlah } \\
\text { Tanggungan }\end{array}$ & $\begin{array}{c}\text { Jumlah } \\
\text { Responden } \\
\text { (Orang) }\end{array}$ & Persentase (\%) \\
\hline $1-2$ & 16 & 80 \\
$3-4$ & 4 & 20 \\
\hline Jumlah & 20 & 100 \\
\hline
\end{tabular}

Sumber Data : Diolah dari data primer 2018

Tabel 3 menunjukkan bahwa jumlah anggota keluarga atau tanggungan keluarga (anak) petani responden antara 1-2 orang yaitu 16 responden atau $80 \%$ dan 3-4 orang yaitu 4 responden atau $20 \%$.

\section{Luas Lahan}

Dalam melakukan suatu usahatani padi sawah, lahan sawah merupakan faktor yang penting untuk menghasikan suatu produksi.

\begin{tabular}{ccc} 
Tabel 4. & $\begin{array}{c}\text { Luas } \\
\text { Kecamatan Rataahan }\end{array}$ & $\begin{array}{c}\text { Lahan Sawah di } \\
\text { Desa }\end{array}$ \\
\hline $\begin{array}{c}\text { Luas Lahan } \\
\text { (Ha) }\end{array}$ & $\begin{array}{c}\text { Jumlah Responden } \\
\text { (Orang) }\end{array}$ & Persentase (\%) \\
\hline $0,5-1,0$ & 15 & 75 \\
$1,1-1,5$ & 3 & 15 \\
$>1,5$ & 2 & 10 \\
\hline Jumlah & 20 & 100 \\
\hline
\end{tabular}

Sumber Data : Diolah dari data primer, 2018
Tabel 4 menunjukkan bahwa sebagian besar petani responden memiliki luas lahan sawah dengan kisaran 0,5-1,0 Ha dengan jumlah petani 15 responden dengan persentase $75 \%$ sedangkan responden yang memiliki luas lahan 1,1-1,5 Ha bejumlah 3 responden dengan persentase $15 \%$, sedangkan $>1,5$ Ha dengan jumlah 2 responden dengan persentase $10 \%$.

\section{Tenaga Kerja Wanita Dalam Usahatani Padi Sawah di Desa Rasi Satu}

Tenaga kerja merupakan salah satu faktor paling utama dalam keberhasilan suatu usahatani, baik itu tenaga kerja laki-laki maupun tenaga kerja wanita. Penelitian ini yang dilihat adalah kegiatan yang dilakukan dalam 1 hari kerja untuk beberapa jenis kegiatan usahatani dengan jam kerja dimulai dari pukul $08.00-17.00$ WITA.

\section{Curahan Waktu Kerja}

Curahan kerja adalah jumlah waktu yang dialokasikan untuk melakukan serangkaian kegiatan yang biasa dilakukan di dalam dan luar rumah tangga dalam satuan waktu atau jam. Jumlah jam kerja yang dicurahkan pada suatu kegiatan dipengaruhi oleh produktivitas tenaga kerja pada kegiatan tersebut, artinya semakin tinggi produktivitas tenaga kerja mendorong orang untuk mencurahkan waktu kerja lebih lama. Curahan waktu dapat dilihat pada Tabel 5.

\begin{tabular}{|c|c|c|c|c|}
\hline No & $\begin{array}{c}\text { Jenis } \\
\text { Pekerjaan }\end{array}$ & $\begin{array}{c}\text { Jumlah } \\
\text { Jam/Periode } \\
\text { Tanam } \\
\end{array}$ & $\begin{array}{c}\text { Rata-rata } \\
\text { Jam/Responden }\end{array}$ & $\begin{array}{c}\text { Persentase } \\
(\%) / J u m l a h \\
\text { jam }\end{array}$ \\
\hline 1 & Persemaian & 60 & 3 & 6,86 \\
\hline 2 & $\begin{array}{l}\text { Pengolahan } \\
\text { Lahan }\end{array}$ & 0 & 0 & 0,00 \\
\hline 3 & Penanaman & 193 & 9,65 & 22,08 \\
\hline 4 & Penyiangan & 177 & 8,85 & 20,26 \\
\hline 5 & Pemupukan & 88 & 4,4 & 10,06 \\
\hline 6 & $\begin{array}{l}\text { Pengendalian } \\
\text { Hama dan } \\
\text { Penyakit }\end{array}$ & 0 & 0 & 0,00 \\
\hline 7 & Panen & 356 & 17,8 & 40,74 \\
\hline & Jumlah & 874 & 43,7 & 100 \\
\hline
\end{tabular}

Sumber Data : Diolah dari data primer, 2018

Hasil penelitian menunjukkan bahwa dalam setiap kegiatan pada usahatani padi sawah di Desa Rasi Satu mulai dari kegiatan persemaian, pengolahan lahan, penanaman, penyiangan, pemupukan, pengendalian hama 
dan penyakit dan panen hanya pada kegiatan pengolahan lahan, dan pengendalian hama dan penyakit wanita tidak berperan, pada kegiatan yang dilakukan responden dalam 1 periode tanam kegiatan yang dilakukan dalam usahatani padi sawah disesuaikan dengan kondisi dan kebutuhan yang ada dikebun.

\section{Kegiatan Persemaian}

Dalam kegiatan persemaian usahatani padi sawah, dilakukan dengan mempersiapkan lahan dan menabur benih dan memelihara persemaian keseluruhan. Dalam penelitian ini dilihat bagaimana tenaga kerja wanita dalam kegiatan persemaian dengan melihat jumlah wanita yang ikut bekerja saat kegiatan persemaian serta jam kerja yang dicurahkan dalam kegiatan tersebut. Tabel 5 menunjukkan jumlah dan persentase waktu dalam kegiatan persemaian.

Hasil penelitian menunjukkan bahwa pada kegiatan persemaian dalam satu periode tanam, jumlah jam yang dicurahkan sebesar 60 jam dengan persentase $6,86 \%$ dari total jam kerja pada usahatani padi sawah dan ratarata 3 jam per responden pada kegiatan persemaian padi sawah.

\section{Kegiatan Pengolahan Tanah}

Dalam kegiatan yang dilakukan dalam pengolahan lahan adalah mencangkul, membajak tanah pertama dan kedua juga menggaru atau menyisir dan meratakan tanah pada tahap pengolahan tanah petani menggunakan tenaga mesin (han tractor). Dalam penelitian ini dilihat bagaimana tenaga kerja wanita dalam kegiatan pengolahan tanah serta jam kerja yang dicurahkan dalam kegiatan tersebut. Tabel 5 menunjukan jumlah dan persentase waktu dalam kegiatan pengolahan lahan.

Hasil penelitian menunjukkan bahwa pada kegiatan pengolahan tanah dalam satu periode tanam, tidak ada wanita yang memberikan curahan waktu kerjanya pada kegiatan ini hanya dilakukan oleh pria, karena pekerjaan pengolahan lahan terlalu berat untuk wanita.

\section{Kegiatan Penanaman}

Dalam kegiatan yang dilakukan dalam penanaman adalah mencabut bibit, memindahkan bibit pada petakan dan menanam bibit padi. Dalam penelitian ini dilihat bagaimana tenaga kerja wanita dalam kegiatan penanaman serta jam kerja yang dicurahkan dalam kegiatan tersebut. Tabel 5 menunjukkan jumlah dan persentase waktu dalam kegiatan penanaman.

Dalam penelitian pada kegiatan penanaman dalam satu periode tanam, jumlah jam yang dicurahkan sebesar 193 jam dengan jumlah persentase jam $22,08 \%$ dan rata-rata 9,65 jam per responden pada kegiatan penanaman padi sawah.

\section{Kegiatan Penyiangan}

Dalam kegiatan penyiangan usahatani padi sawah, kegiatan ini merupakan pekerjaan mencabut rumput atau tanaman tanaman liar diantara tanaman padi. Pekerjaan penyiangan biasanya dilakukan pada saat tanaman berumur 2 - 4 minggu. Dalam penelitian ini dilihat bagaimana jumlah wanita yang bekerja saat kegiatan penyiangan serta jam kerja yang dicurahkan dalam kegiatan penyiangan tersebut. Tabel 5 menunjukan jumlah dan persentase waktu kerja wanita dalam kegiatan penyiangan.

Dalam peneitan pada kegiatan penyiangan dalam satu periode, jumlah jam yang dicurahkan sebesar 177 jam dengan persentase jam 20,26\% dan rata-rata sebesar 8,85 jam per responden pada kegiatan penyiangan padi sawah dengan mencabut rumput yang ada di sekitar atau ditengah tanaman.

\section{Kegiatan Pemupukan}

Kegiatan pemupukan dilakukan $2-3$ kali, namun kenyataan dilapangan menunjukan bahwa responden melakukan sebanyak 3 kali. Dalam penelitian ini dilihat jumlah wanita yang ikut bekerja saat kegiatan pemupukan serta jam kerja yang dicurahkan dalam kegiatan pemupukan tersebut.

Dalam penelitian pada kegiatan pemupukan dalam satu periode tanam, jumlah jam yang di curahkan sebesar 88 jam dengan persentase sebesar 10,06\% dan rata-rata jam per responden sebesar 4,4 jam pada kegiatan padi sawah. 


\section{Kegiatan Pengendalian Hama dan Penyakit} Kegiatan yang dilakukan dalam pengendalian hama dan penyakit adalah penyemprotan pestisida pada tanaman. Dalam penelitian ini ingin dilihat bagaimana tenaga kerja wanita dalam kegiatan pengendalian hama dan penyakit yaitu dengan melihat jumlah jam kerja yang dicurahkan dalam kegiatan pengendalian hama dan penyakit. Tabel 5 menunjukan jumlah persentase waktu kerja wanita dalam kegiatan pengendalian hama dan penyakit.

Hasil penelitian menunjukan bahwa dalam satu periode tanam, pada saat kegiatan pengendalian hama dan penyakit, tidak ada wanita yang ikut berperan atau memberikan curahan waktu kerjanya pada kegiatan pengendalian hama dan penyakit. Pada kegiatan pengendalian hama dan penyakit di Desa Rasi Satu bahwa pada kegiatan ini hanya dilakukan oleh pria.

\section{Kegiatan Panen}

Tabel 5 menunjukan jumlah dan persentase waktu kerja wanita dalam kegiatan panen. Kegiatan panen diakukan dengan cara menunggu 3-4 bulan dari waktu penanaman dan melihat daun yang sudah menguning dan tanaman yang sudah berisih juga mulai menguning dan menunduk itu bertandah padi sudah siap untuk di panen.

Dalam penelitia pada kegiatan panen dengan jumlah jam yang dicurahkan sebesar 356 jam dengan persentase jam 40,74\% dan rata-rata jam 17,8 jam per responden dalam kegiatan panen usahatani padi sawah.

\section{Kegiatan Wanita di Luar Usahatani}

Sebagai seorang ibu rumah tangga wanita tidak terlepas dari kewajiban dan tanggung jawab yang wajib dilakukan yaitu dalam pekerjaan mengurus rumah tangga seperti, memasak, membuat kopi, dan mengurus anak.

Dalam penelitian ini jam kerja wanita diluar usahatani, 20 responden pada pagi dan sore hari melakukan kegiatan memasak, membersikan rumah, mengurus anak, menyiapkan kopi atau teh.

\section{KESIMPULAN DAN SARAN}

\section{Kesimpulan}

Hasil penelitian menunjukkan bahwa curahan waktu kerja wanita dalam usahatani padi sawah di Desa Rasi Satu yaitu pada kegiatan $6,86 \%$ persemaian, 22,08\% penanaman, $20,26 \%$ penyiangan, $10,06 \%$ pemupukan, 40,74\% panen. Pengolahan lahan, dan pengendalian hama dan penyakit hanya dilakukan oleh laki-laki.

\section{Saran}

Diharapkan pada kegiatan pengendalian hama dan penyakit tidak hanya dilakukan oleh pria saja tetapi wanita juga ikut berperan.

\section{DAFTAR PUSTAKA}

Novita R. 2012. Faktor-Faktor Yang Mempengaruhi Curahan Waktu Kerja Wanita Tani Pada Usahatani Padi Sawah (Studi Kasus Di Desa Ngarjo Kecamatan Mojoanyar Kabupaten Mojokerto). Universitas Briwijaya. Malang.

Sendow M. Martha. 2001. Peranan Wanita Pada Usaha Tani Padi Sawah di Kecamatan Tompaso Kabupaten Minahasa.

Sudarta W. 2003. Peranan Wanita Dalam Pembangunan Berwawasan Gender. Jurnal Studi Jender SRIKANDI. Fakultas Pertanian Universitas Udayana. 